\title{
La mujer collage. Perspectivas críticas sobre el cuerpo femenino en las novelas de Cambaceres
}

\author{
The collage woman. Critical perspectives on the \\ female body in the novels of Cambaceres
}

\author{
Mariana RosetTI \\ Universidad de Buenos Aires-CONICET. Buenos Aires, Argentina \\ marurosetti@gmail.com
}

\section{RESUMEN}

El presente trabajo se propone analizar el tipo de representación estética que construye Cambaceres en sus novelas para indagar sobre las distintas perspectivas críticas que la misma asume sobre el cuerpo femenino en consonancia con la crisis de la representación de la patria manejada por la generación del '80. El objetivo es mirar más allá de la visión misógina y biográfica que se ha sostenido sobre este autor (en aspectos "morales" o "éticos" alrededor de la figura femenina) para analizar el lugar simbólico que ocupan las mujeres dentro de las obras del mismo como metáfora de los cambios sociales, económicos y políticos acaecidos en Argentina a fines del siglo XIX.

Palabras clave: Generación del '80, representación de la patria, cuerpo femenino, desvío.

\section{ABSTRACT}

The present work researches the particular kind of aesthetics representation that developed Cambaceres in his novels to inquire about the different critique perspectives of dealing with the female body in consistent with the crisis of the representation of the homeland elaborated by the "generación del ' 80 ". The purpose of this research is to go beyond the biographic and misogynous vision that was "attached" to the novels 
of this author. We will analyze the symbolic place and the role that female characters play in these books as a metaphor of the social, economic and political changes that took place in Argentina at the end of the XIX century.

Keywords: Generación del '80, representation of the homeland, female body, deviation.

Recibido: 20.11.2012. Aceptado: 25.06.2013.

\section{PINTAR LA ALDEA CON TRAZOS ABERRANTES. FICCIONES FUNDACIONALES DE LA DISIDENCIA}

El campo de observación es tan vasto y tan inexplorado entre nosotros, que me da una pena profunda ver un hombre tan bien dotado, que es hoy un escritor completo, con todos sus defectos de estilo, desviarse con deliberado propósito, pintar llagas inmundas ante una sociedad como la nuestra, la que más necesita la prédica incansable del ideal (Miguel Cané, "Sección literaria": Música sentimental").

Mal que les pese, todos Uds. han colaborado alcanzándome la pintura (Eugenio Cambaceres, “Dos palabras del autor”, Pot-pourri).

M ucho se ha hablado y escrito sobre la estética a la que responde Cambaceres en sus novelas. Mientras que algunos críticos observan su trayectoria de escritura como un continuum o evolución que va del naturalismo al decadentismo, otros destacan su particular forma de "adaptar" las corrientes literarias provenientes de Europa para crear de ellas un estilo propio $^{2}$ que redefine la identidad nacional hacia el interior de la clase dirigente ${ }^{3}$.

${ }^{1}$ Cané, Miguel, “Sección literaria”: Música sentimental, Sud-América, 30/9/1884 (reproducido fragmentariamente en Cymerman, 1973-1974).

${ }^{2}$ Como es el caso de los estudios críticos de Cymerman, 1973-1974; Marun, 1986; Jitrik, 1997; Panesi, 2004; Iglesia, 2003; Laera, 2004 y David Solodkow, 2011; entre otros.

${ }^{3}$ David Solodkow (2011) considera la (re)definición de la identidad nacional como el paso necesario del proyecto naturalista de Eugenio Cambaceres que, a modo de alarma clasista, se permeabiliza del Otro inmigrante: "En este sentido, creo que existen argumentos para probar que en 
Lo cierto es que ninguna de las posturas críticas sobre la obra de este autor niega su proceso de "extrañamiento", de "descentralización", que ha ejercido en relación con el canon establecido por la generación del ' 80 y su poética "melancólica" y esteticista de la mano de Miguel Cané y Pedro Goyena, entre otros. Al respecto, las palabras de Cristina Iglesia (2003) resultan muy precisas para dar cuenta de ello:

[...] al moverse contradictoriamente desde el lugar del vago silbador hacia el representante de la escuela naturalista, que no trabaja con silbidos sino con buriles, Cambaceres diseña un lugar híbrido desde el que su gesto, su texto, deberían ser leídos. No alcanza a entender que al atacarlo, nadie habla de escuelas literarias. Se habla de otra cosa [...] (Iglesia, 2003: 120) (énfasis mío).

De lo que "se hablaba", según lo plantea Iglesia en su artículo, era de "defender los límites" de lo representable, de cercarlo. Ello nos lleva a reflexionar sobre el lugar que ocupa el discurso literario para esta "coalición del '80", destacando que dicho grupo de escritores todavía pertenece a la "República de las letras" en donde "las letras eran un dispositivo disciplinario, requerido para la constitución de los sujetos de ley [...]” (Ramos, 2003: 63). Sin embargo, dentro de este entramado discursivo de poder, Cambaceres escribe desde los márgenes, desde aquellos lugares donde la voz narradora ya no persigue un fin elitista e idealista sino escandalosamente contemplativo, espacios narrativos en los que la ficción dialoga de manera conflictiva con el buen gusto y con los fines pedagógicos y civilizatorios de su propio grupo social e intelectual. En relación con esta "escritura fronteriza", que juguetea entre la mismidad aristocrática y la otredad burguesa/inmigrante arribista, Alejandra Laera (2004) elabora el concepto de ficciones liminares ${ }^{4}$ :

[...] es decir, novelas en las que se produce ficción en los umbrales de la ficción, $[\ldots]$ en una zona fronteriza entre lo real y lo ficcional, en una zona de

el proyecto naturalista de Eugenio Cambaceres (1843-1889) -fundamentalmente su última novela, En la sangre (1887) - puede ser considerado como una etnografía finisecular, el cual, bajo los imperativos ideológicos de la oligarquía vernácula, describe la inminencia de un peligro a conjurar: el Otro inmigrante" (93).

${ }^{4}$ Este concepto Alejandra Laera (2004) lo elabora y aplica para analizar las novelas de Eugenio Cambaceres y de Eduardo Gutiérrez o, como ella lo señala, las dos series de ficción que se organizan a lo largo de los años de 1880 en Argentina y que funcionarían como divisoria de aguas entre formas ficcionales, poéticas y públicos: la novela popular y la novela moderna de la alta cultura (20). Cambaceres contribuiría a consolidar la segunda serie. 
negociación en la cual construyen sus representaciones. Porque sus novelas necesitan crear primero un espacio "preliminar" para constituir desde allí la ficción: negociación de subjetividades "reales" y ficticias para empezar a narrar [...] Ese límite, lo liminar, es la zona de un desacomodamiento que se narra como tal entre la realidad y la ficción. Allí no hay garantía de estabilidad ni de cohesión, sólo desvíos [...] Si, según la lectura de Doris Sommer, las ficciones fundacionales articulaban novela y nación en los matrimonios heterosexuales y en su productividad sexual, las novelas a través de las cuales se constituye el género plantean lo contrario: están protagonizadas por hombres solos que han elegido el celibato o que se han visto obligados a abandonar su hogar, tratan de matrimonios que caen en la mutua infidelidad y de hijos que mueren o nunca llegan a nacer. La novela ya no es, como alguna vez se quiso, el equivalente alegórico y totalizador de la nación y sus identidades, sino que opera sobre los restos y los huecos que el Estado modernizador de los años ochenta practica en la reconfiguración de lo nacional. Por eso, si las ficciones liminares son aquellas que constituyen a la novela como género en la zona fronteriza entre lo real y la pura ficción, es porque, sin antecedentes ni genealogía, el espacio de la ficción debe ser inventado en los propios textos para poder contar aquello que los otros géneros y las otras novelas de la época no quieren ni pueden contar (21-23) (énfasis míos).

Esta estética del desvio le permitirá a Cambaceres erigir un narrador ascético que "husmee" con su mirada miope en los pliegues y recovecos de la imagen consolidada de la sociedad y sus núcleos representativos (como son la familia, la institución del matrimonio y la conformación y consolidación del sistema republicano) para focalizarse sobre aquellos accionares que deberían permanecer obturados, ocultos. Dicha perspectiva se une, retomando lo sostenido por Iglesia (2003), con el lugar de lo hibrido, con la mezcla impensada que disloca y genera una resignificación de los elementos dados. Para profundizar esta mirada, Laera (2004) sostiene que este autor trabaja construyendo un "retrato aberrante" ya que: "Como un fotógrafo en bús-

${ }^{5}$ Laera (2004) analiza este tipo de mirada miope y difusa mediante la cual el narrador construye una focalización descentrada que organiza la lectura del cuerpo y que impide distinguir las diferencias entre los sujetos de la escena social como parodia de la mirada minuciosa y determinista tanto del parvenu o arribista burgués como del aristócrata que ve peligrado su lugar de privilegio social. A modo de ejemplo, Laera destaca la mirada del arribista en el capítulo VI de Pot-pourri: mientras que este "cree en la posibilidad del reconocimiento de la sangre en el cuerpo y por eso confía en lo que ve, en lo que se deja ver, el narrador busca formas donde el otro solo puede ver colores [...]" (266). 
queda de nuevas técnicas expresivas, Cambaceres expone las aberraciones tonales de la luz artificial, encontrando en el "carnaval" una figura apta para establecer analogías entre una escena social y artificiosa y el funcionamiento de la sociedad de la época que reproduce" $(257)^{6}$. Es decir, en las novelas de este escritor el concepto de lo híbrido se escinde del aspecto productivo de las ficciones fundacionales, que tematizan el nacimiento de una nación, para plantear desvíos propios de la reproducción (sea en sus aspectos sociales, técnicos o formales). Esto es, la escritura de Cambaceres presenta las múltiples aristas de la reproducción o "farsa monstruosa" que practican los diversos "otros" sociales dentro del sistema republicano, considerado por este escritor como un "gran carnaval" que dificulta el reconocimiento de los cuerpos y su correcta ubicación dentro del espacio social y urbano. El ingreso abrupto a la modernidad y la instalación del sistema republicano habilitarían mezclas sociales incontrolables por la elite dirigente así como también simulaciones y representaciones posibles a ser realizadas por actores sociales impensados como son los inmigrantes, los nuevos burgueses criollos y, sobre todo, los "otros endógenos", propios del mismo grupo de la "coalición del '80": las mujeres de la familia aristocrática ${ }^{7}$. La unión de este grupo defendido por ciertos escritores, como son Goyena y Cané, se transformará dentro de la narrativa de Cambaceres en una homogeneidad fracturada imposible de permanecer oculta y silenciada.

Esta relación entre lo artificial y el carnaval deviene fundamental para analizar la obra de Cambaceres ya que nos sitúa en el espacio donde se trasviste el sistema desde su interior. Es decir, este tipo de festejo posee una lógica de caos que se encuentra avalada por el poder que lo instaura y contiene. Para ser más precisos, en las novelas de este autor se observa un "accionar carnavalesco" que debe permanecer dentro de lo confinado del hogar, como un secreto, pero que se escurre por los huecos de las paredes o muros del recinto familiar. Este "secreto a voces" habilitaría la estética del silbador, los chismes y, en definitiva, el discurso literario, que trabajará con aquellos elementos no comprobados, ni certificados pero no por eso atrapantes y "deliciosos" para la voracidad lectora.

Lo interesante de esta nueva focalización y posicionamiento de la na-

${ }^{6}$ En palabras de Cambaceres: "Decía, pues, que había tenido los bultos por delante, sólo que, operando en carnaval, en que todo se cambia y se deforma, probablemente se deformaron también las lentes de mi maquinaria, saliendo los negativos algo alterados de forma y un tanto cargados de sombra" (2001: 13).

${ }^{7}$ Tomamos al respecto la perspectiva de Laera (2004): “[...] el retrato del grupo (del ochenta) es aberrante porque responde a la ley de la reproducción y no porque se aparte de ella [...] el acto de reproducir exhibe identidades anómalas" (260). 
rrativa ficcional es que permite la construcción de "ficciones fundacionales disidentes" que desmontan el armado de la institución familiar, lo desmenuzan y exponen sus grietas desde un lugar irónico y mordaz mostrando así el fracaso de la identificación de la unidad familiar con la unidad de la patria. Así, se destacan las múltiples críticas que los narradores de las obras de Cambaceres hacen sobre la familia como envoltura irónica de una patria sin cuerpo ni contenido y como pérdida irreparable de esa gran aldea aristocrática que fue para Lucio V. López la ciudad de Buenos Aires:

-El hombre que se casa se embarca, y el que se embarca peligra- agregué en tono sentencioso.

-Sí, pero el que no se embarca no atraviesa el mar.

-Mejor es no atravesarlo, que ahogarse en él.

-Eso no pasa de ser un detestable lugar común [...]

-Te ayudaré a bien morir, haciendo los más fervientes votos para que todas las bendiciones del cielo se derramen sobre tu cabeza (2001: 27).

[...] el hogar, la familia, se convierten en un asunto de plata que irrita, donde se llega hasta decir: Fulano ha hecho un magnífico negocio, se ha casado con tantas mil libras de rentas, aunque esas tantas mil libras de renta vengan a ser el precio de su porvenir y de su vida indecentemente vendidos a un ser enfermizo y ruin y de ese pacto monstruoso salgan hijos escrofulosos y raquíticos (1884: 4).

[...] la infame lo había hecho eternamente desdichado, en un momento había echado por tierra sus más gratas ilusiones, envenenado su existencia, cubierto su nombre de ignominia, lo había traidoramente escarnecido, deshonrado a él, un noble, un conde, un hijo de ilustre raza; a él, que todo lo abandonara, porvenir, familia, patria, que todo sacrificara por ella... y tanto y tanto que la había querido... infame, infame, infame!... (1980: 79).

Este tipo de representación implica un quiebre en relación con el "retrato familiar- literario" que circula en la elite gobernante y que posee el objetivo de conformar un cierto "museo" representativo de figuras emblemáticas. Dentro de este linaje, encontramos la obra de Paul Groussac (1972), Los que pasaban, que si bien presenta por momentos ribetes cómicos sobre las figuras políticas de las que habla ${ }^{8}$, dichas "licencias" las realiza dentro de un

\footnotetext{
8 "Sea de ello lo que fuere, no se trata sino de detalles accesorios al lado del asunto principal, que consistía [...] en destacar del fondo contemporáneo algunas figuras argentinas, acaso con mayor relieve y colorido del acostumbrado, gracias a la substitución de la tiesura y empaque oficial del
} 
marco de respeto y admiración filiar. Es decir, los tipos de retratos que circulan en su obra ensalzan determinadas figuras políticas y culturales que se vuelven a los ojos del escritor ejemplos a seguir para sus lectores familiares, pertenecientes a la misma elite de poder:

No quise, como digo, escribir esta vez sino de los que habían sido amigos míos, evocándolos preferentemente en aquellas circunstancias y escenas de que pudiera yo dar fe como testigo presencial, cuando no como actor. Con esto se explica y justifica el que aparezca frecuentemente, el biógrafo junto al biografiado, a imitación de esos cuadros en que el pintor desliza su propio retrato entre un grupo de espectadores (Groussac, 1972: 11).

La cita nos sitúa en una producción cultural "endogámica” donde la literatura cumple un fin estético y también de reafirmación de los lazos filiares simbólicos entre un grupo cerrado de personas que detentan el poder y los parámetros de la cultura.

A modo de tergiversación, encontramos la postura estética de Cambaceres que plantea una representación de ciertas figuras de un espectro social. Dicha elaboración literaria no deviene en "modelo" a seguir sino en fragmentación, en resquebrajamiento de la imagen consolidada de lo que todo hombre o mujer debía aspirar a ser. Debido a ello, Laera caracteriza el tipo de retrato generado por Cambaceres como "aberrante" ya que desestabiliza y "moviliza" al espectador/lector. Alejándose de la estética mimética, que añora asimilarse a la realidad y volverse "una" con ella, este autor trabaja con una estética "deformada", desviada de la "armonía clásica" esperada y trabajada por Cané en sus obras. Una de las formas de vehiculizar el impacto de este retrato o pintura con trazos aberrantes que propone este autor sobre la antigua gran aldea aristocrática, es observar el nuevo tipo de lector que se construye en sus relatos (en especial en su primera novela, Pot-pourri). Este lector no se presenta ya como fiel espejo de admiración y respeto de las enseñanzas del narrador, sino como juez y verdugo de la sociedad que habita: "Si dijera que el programa se llenó en todas sus partes, de acuerdo con lo prometido por la empresa, mentiría descaradamente. A ustedes los nombro jueces [...] Forme Ud. conciencia como juez de la misma y eche mano de ella para decir a un marido [...]" (Cambaceres, 2001: 105 y 120).

En el marco de esta "representación aberrante", Cambaceres plantea la irrefrenable apertura republicana de la sociedad mostrando el accionar de

personaje por los rasgos familiares de la persona" (Groussac, 1972: 12). 
ese otro silenciado y ocultado (la mujer, el inmigrante, el arribista) por la retórica del grupo del '80 tanto como una alarma clasista como una denuncia sobre el anacronismo de un modelo estanco de sociedad propuesta por los idealistas aristocráticos. Así, estipula de forma irónica una nueva sociedad de pares: “¿Mis iguales? Mis iguales eran todos ahora, era cualquiera. Contagiado, manchado yo también, podía tenderles la mano y confundirme con ellos en un abrazo común" (1884: 58).

En base a esta perspectiva crítica y mordaz, analizaremos las distintas construcciones que se elaboran en las novelas de Cambaceres sobre el cuerpo femenino, entendiéndolo como analogía de la crisis de la patria argentina, concepto que se debe resguardar para la coalición del ' 80 por considerarla una entidad en peligro. Nuestro objetivo es mirar más allá de la conclusión a la que varios han arribado sobre la visión misógina del autor para con los personajes femeninos. Por ello, este trabajo no se centrará en aspectos "morales" o "éticos" alrededor de la figura femenina sino que analizará el lugar simbólico y desestabilizador que ocupan las mismas dentro de las obras de dicho autor y qué rol juegan para los personajes masculinos en el entramado novelesco. En consecuencia, nos centraremos en la elaboración que realiza este autor sobre el cuerpo femenino considerándolo como un "modelo para armar" que constantemente se intenta confinar en una perspectiva y forma conservadora (la mujer angelical/la mujer diabólica). La repetición de este modelo dualista y estático a lo largo de sus cuatro novelas nos muestra las dificultades que ha tenido la generación del ' 80 para controlar a este "otro" que no acepta ceñirse a los límites domésticos impuestos ${ }^{10}$. A su vez, esta iteración dará lugar a la estética moderna del "collage" que presenta al cuerpo femenino como la colisión de fragmentos deseables y detestables para la mirada masculina, como una suerte de desenmascaramiento de la farsa del poder. Así, se destacan como marco de reflexión de nuestro análisis los siguientes fragmentos de las novelas de este escritor:

${ }^{9}$ En juego con la perspectiva de Cortázar que retoma la escritura de Cambaceres para dar cuenta del lugar femenino dentro de un mundo de hombres (las vinculaciones entre estos dos estilos literarios las analizan tanto Iglesia (2003) como Laera (2004).

10 "Toda la novedad que presentan la estructura de la novela y sus entramados críticos se desvanece a la hora de representar a las mujeres, a quienes el narrador encuadra en un esquema propio de la época: éstas solo podrán ser ángeles o demonios: las dos caras de una misma moneda" (Torre, 2001: 8). Tenemos en cuenta esta observación de Claudia Torre como el deseo de Cambaceres de mantener el accionar femenino y su representación dentro de una perspectiva conservadora. Deseo conservador que dialogará con la estética del collage que se irá construyendo en la narrativa de este autor. 
Fuera de hipérboles, metáforas y figurones. Nada de ébanos, alabastros, perlas, corales, sílfides, soles y demás pavadas que todo el que empuña una pluma, en prosa o en verso, se cree con derecho a arrastrar de los cabellos en obsequio a las heroínas de sus engendros espirituales [...] No hay mujer que sea sujeta de mostrar un pelo de ébano, un cutis como alabastro, unos dientes como perlas, unos labios como corales, un cuerpo como sílfide, ni unos ojos como sol; cuando mucho, se podría decir de los más lustrosos que alumbran como una vela de sebo y gracias. La que más, la que menos, todas tienen sus cosas feas, a la vista o escondidas (2001: 81).

La quiero irreflexiva, ciega, instintivamente, no por ella -no la querría si fuera picada de viruelas o tuerta- sino por mí y para mí, para mí solo. Y la idea de su pasado, de que eso que es mío ahora ha sido de todos antes, que medio mundo ha metido la mano allí hasta el codo y ha sacado su ración, lo mismo que en un bodrio a la puerta de un convento, me carga y me desespera. Y tengo celos entonces, celos de toda la tropa de sus amantes, celos hasta de usted que la ha conocido primero. Quisiera... ¡qué sé yo!... Que no fuera ella, que fuera otra, verla nacer y crecer de nuevo ante mis ojos para arrancarle yo los secretos de su virginidad, para aspirar el cáliz de su cuerpo de mujer, lejos hasta del aire que los otros respiran, como esas plantas de invernáculo cuyas flores corta y marchita solo la mano egoísta de su dueño. Y tira al cajón de la basura cuando empiezan a oler a viejo (1884: 90).

\title{
LA MODERNIDAD Y LA ECONOMÍA DE LOS CUERPOS
}

\begin{abstract}
Buenos Aires aparece como una ciudad inmensa que se ha lanzado a la lucha por la vida con una pasmosa actividad [...]; los vehículos que no caben en las calles estrechas; y los carruajes de la calle de Florida; y las tiendas cuajadas de damas; y los espléndidos escaparates; y las mujeres, admirables del botín al sombrero [...] y todo esto confundido, a prisa, pasando como una fantasmagoría (D’Amico, 1977: 8).
\end{abstract}

En sus novelas Cambaceres presenta una imagen maniquea sobre el cuerpo femenino: el "cuerpo libertino" (representado por la "mujer pública" y trabajado en particular en Música sentimental) versus el "cuerpo institucio- 
nalizado" (representado por María y Máxima en Pot-pourri y En la sangre, respectivamente). Cada uno de estos cuerpos se ve signado por obligaciones y accionares distintos: mientras la "mujer pública" se ve obligada a proporcionarle al hombre un placer pasajero y a no inmiscuirse en su vida; la "mujer familiar" debe abocarse al hogar y administrarlo.

A pesar de esta diferenciación entre cuerpos externos y cuerpos propios del circuito familiar, en estas novelas el narrador recurre a una analogía frecuente para referirse al cuerpo femenino: asimilarlo a un objeto. El mismo puede tener un uso "dinámico", como "medio de transporte" (así encontramos la analogía de la mujer con un coche de plaza), o, por el contrario, se lo puede confinar a la pasividad del recinto hogareño en donde el cuerpo femenino adquiere la adjetivación de "mueble de uso". Al respecto, se observan ciertos fragmentos novelescos de Pot-pourri: "[...] Porque las mujeres no son como los pollos, que uno alcanza para dos amigos. Nosotros, los del sexo, no queremos saber de bromas al respecto. Entendemos que el mueble nos pertenece, que es de nuestro uso exclusivo y no hay más" (2001: 121) y de Música sentimental: "Las mujeres, mi querido señor Pablo, son el coche de los hombres. Vivir sin ellas es andar a pie. A lo mejor, se cansa uno, se sienta, se aplasta y se tiende a la bartola" (1884: 26). Estas asimilaciones que cosifican el cuerpo femenino actúan como remedos del accionar peligroso de la mujer trepadora: "Las yerbas esas nos invaden poco a poco por el tronco, se nos adhieren, se nos pegan, van creciendo, se entretejen, se enredan, se enmarañan y acaban por subirse a la corona y por desparramarse en la copa chupándonos toda la savia” (1884: 26).

Las citas antedichas configuran a un narrador experimentado que ha vivido y que conoce el astuto proceder femenino. Sin embargo, las "enseñanzas" que dicha voz masculina despliega para con sus acólitos ni son escuchadas por los mismos (Pablo se inmiscuye con Loulou, Juan se casa con María) ni los personajes femeninos se comportan como "objetos de uso" y decoración de un ambiente, como desea el narrador, sino que deambulan, se movilizan entre los espacios y se desvían de las conductas esperables para ellas. Así, los consejos del narrador devienen una excesiva "ornamentación" de una narración donde las mujeres actúan por fuera de lo esperado, en los márgenes inaprehensibles de su saber vivencial, fracturando así el imaginario y "sabiduría vivencial" del hombre experimentado. El "accionar desviado" e impensado de las mujeres presenta el fracaso del narrador de querer encuadrarlas dentro del espacio dualista de la "mujer pública" y la "mujer del hogar": "La mujer esta es algo peor, es un saguaipé que se me ha prendido, no en el bolsillo, sino en el corazón y que me está chupando la paciencia. Soy víctima de la 
más inicua explotación de sentimientos que se haya inventado hasta la fecha [...] es un dechado de virtudes domésticas, un modelo acabado de perfecciones" (1884: 42) (énfasis mío).

De esta forma, se suele ver en la narrativa de Cambaceres un conflicto entre la "mujer habitada" (o mujer casada) y la "mujer a evitar" ("mujer pública") que gira en torno a presentar al cuerpo femenino como el equivalente a un hogar que debe ser vigilado para que no ingrese en él ningún extraño: "Ha enajenado el uso de su persona, ha firmado un contrato de alquiler, ni más ni menos, que si fuera una casa, contrato en virtud del cual no puede Ud. ser afectada a otros objetos que aquéllos a que expresamente la destine su inquilino" (2001: 140).

Las analogías de la mujer con un objeto a poseer resultan cruciales para entender el rol simbólico que juegan las mismas en la sociedad y para con los hombres. Al respecto, contribuye una idea extraída del prólogo de Susana García y Jorge Panesi (2007) de la novela En la sangre: "El espacio al que el personaje accede en su ascenso le presenta vallas o barreras que deberá sortear [...]" (36). Si bien esta cita enmarca una obra narrativa en donde el protagonista, Genaro, realiza una "carrera de ascenso" en la escala social, lo cierto es que en las novelas de este Cambaceres se representa el espacio masculino dominado por la modalidad evaluativa en la que el personaje (Genaro, Pablo, Juan, Andrés) se muestra deseoso de sortear exitosamente la "barrera social" que concentra la mirada de sus evaluadores. Para lograrlo se vuelve necesario recurrir a la figura femenina que actúa como el pasaje, el cuerpo intermediario, entre el ser y el parecer del hombre.

Sin embargo, este carácter del cuerpo femenino de ser el eslabón o, si se quiere, el "trampolín" del personaje masculino a otro espacio y realidad social, conllevará un extrañamiento por partida doble: ni la mujer deviene, como se pensaba, en "artefacto" del hogar, ni su unión o mezcla con el hombre le otorgan un orden moral o religioso. Es decir, deviene en "intermediaria" de manera "forzosa": el acto de unión se ve rodeado de una violencia y un engaño inusuales de parte del personaje masculino (Andrés se inmiscuye en el rancho de Donata hija de un empleado suyo; Genaro fuerza a Máxima en el Club del Progreso; Juan "extirpa" a María del seno hogareño). En dicho acto, la mujer es considerada un instrumento no meramente de placer sino de transporte, desde un "pasatiempo" (Andrés) como un pasaje a otro tipo de vida. Si bien este violento acto sexual no estaría ligado a la unión carnal que se produce entre Loulou y Pablo en Música sentimental, sí lo estará la relación posterior que conformen donde él demostrará una pasión desenfrenada. 
Este gesto de movilización que ejerce la mujer sobre el hombre presenta una contrapartida en el accionar inesperado de las mismas: así como sirven de "pasajes" cobran su "peaje", es decir, se transforman en seres que desean, exigen y, por sobre todo, se "corporalizan" a los ojos del narrador: es así como Loulou pasa de ser una "mujer pública" a una "ama de casa", "convirtiendo el gasto lujurioso de Pablo en "economía doméstica" (Laera, 2004: 275); Máxima regula, exponiendo su cuerpo, el dinero otorgado a Genaro; Donata, si bien fallecida al nacer Andrea, le delega a Andrés la tarea de criarla y, finalmente, María se escabulle del hogar simulado para encontrarse con su amante.

Dicho gesto de contrapartida (de hacerse visibles a los ojos masculinos) se contrapone a la visión decadente y apocalíptica que ciertos intelectuales de la época (Cané, D’Amico, Goyena) solían asociarle a la mujer como consecuencia de los tiempos fluctuantes y modernos. Dentro de esta perspectiva, la mujer al igual que otros "objetos" tradicionales y de valor se disuelve y fragmenta debido a la invasión de elementos nuevos (población, objetos materiales, medios de transporte) y de una modalidad temporal que aceleran y resquebrajan la "paz hogareña".

En el capítulo "El lamento de Cané”, Oscar Terán (2000) delinea la división que se produce en la sociedad y en el circuito de poder a mediados de los ' 80 y las repercusiones acaecidas debido a los cambios en los planos social, económico y cultural. Como se plasma en este artículo, los ejes espacio-tiempo se ven trastocados generando una disolución, para algunos, de aquella unión cultural y política tan familiar a merced de diversos elementos (en particular los aluviones inmigratorios y la ascensión social y económica de "advenedizos") que dan cuenta del ingreso del país a la modernidad ${ }^{11}$. En consecuencia, los valores "estamentales" se ven trastocados por un torbellino de modificaciones aceleradas y fugaces donde prima el lujo por sobre la "sustancia espiritual".

En respuesta a la temporalidad caótica que domina, estos intelectuales llevan a cabo un trabajo ideológico-cultural consistente en resolver este enigma (en cierta medida "trágico" para varios): ¿cómo definir la noción de aristocracia en un país republicano? Si los bienes materiales y el lujo se configuran como propios de una existencia vulgar y efímera, lo extraordinario (en todos los sentidos de la palabra) debe provenir de valores culturales y

${ }^{11}$ En relación con los cambios percibidos de manera apocalíptica e irrefrenable, Calzadilla elabora un cuestionamiento que rondará por la mente de muchos intelectuales de la generación del '80: “¿Cómo es posible que en ese kaleidoscopio constante se llegue a la sensación del hogar?” (1982: 161) (énfasis mío). 
estéticos que ligan a los portadores de dicho saber con un pasado ya perdido y devenido en utopía y mitología recuperables, solamente, a través de recuerdos y narraciones. Se constituye de esta forma un tipo de nacionalismo culturalista y esencialista que se contrapone al universalista o imitativo. Dentro de este tipo de nacionalismo los intelectuales juegan el rol de maestros de la juventud, cual Próspero con Ariel. Sin embargo, esta postura de "nacionalismo culturalista" es paradójica ya que se construye en base a un concepto de ciudadano "pastiche":

La combinación de conservadorismo y liberalismo generó actitudes muchas veces contradictorias. La élite transformadora no aprobó la existencia de un orden social sancionado por una religión establecida, pero estaba convencida, pese a todo, de la imperfecta naturaleza del hombre y de la desigualdad que imperaba en la sociedad [...] (Botana, 1985: 14).

Esta "lucha agónica" (entre el héroe intelectual y la ciudad sin estamentos ni valores perdurables) genera en Cané una analogía negativa entre el cuerpo femenino y la patria "que se comunican por la posesión de calidades semejantes (linaje, castidad), ambos al mismo tiempo amenazados por los turbios materialismos de la economía y la lascivia" (Terán, 2000: 54). Dentro de esta mirada, la mujer se presenta indefensa frente a las amenazas externas ya que, al igual que la patria, consta de valores y de una corporeidad "etérea", intangible.

En contraposición a esta postura irreductible y estática, Cambaceres nos muestra en sus novelas mujeres que desean, que reclaman, cuya fortaleza no se concentra en lo "puro" (con sus respectivas connotaciones sexuales), sino en lo desarmable, en lo dinámico. Estas características chocan con la perspectiva aristocrática que predominaba sobre el cuerpo femenino y reclaman la reconfiguración de la mirada masculina sobre el espacio simbólico y social a ejercer por la mujer:

Y como si la mujer fuera un cero a la izquierda, algo de poco más o menos y no debiera ejercer la maldita influencia en la familia y, por consecuencia, en la sociedad, en su marcha y perfeccionamiento, es así como tratamos de levantar su nivel moral [...] ¿Qué nos importa que en otras partes, en los Estados Unidos, por ejemplo, que tenemos a gala de plagiar, muchas veces sin ton ni son como los monos, la dignifiquen hasta el punto de preocuparse de sus derechos políticos y hacer de ella altos funcionarios públicos, médicos, abogados, etc.? A nosotros nos acomoda y da la regalada gana 
tenerla en cuenta como una cosa. ¿Por qué? Porque sí, porque la rutina es un vicio inveterado en nuestra sangre y porque tal era la antigua usanza de nuestros padres los españoles de marras (2001: 32).

\section{ENTRE LO ETÉREO Y LO MONSTRUOSO: LA “MUJER COLLAGE”}

Mira, nuestro deber sagrado, primero, arriba de todos, es defender nuestras mujeres contra la invasión tosca del mundo heterogéneo, cosmopolita, híbrido, que es hoy la base de nuestro país [...] Salvemos nuestro predominio legítimo, no sólo desenvolviendo y nutriendo nuestro espíritu cuando es posible, sino colocando a nuestras mujeres, por la veneración, a una altura a que no llegan las bajas aspiraciones de la turba [...] Cerremos el círculo y velemos sobre él (Miguel Cané (1884), “De cepa criolla”, en Prosa ligera, $\left.1919^{12}\right)$.

[...] sáquele el cuerpo al collage o, cuando menos, mire con quien se cuela; no hay nada más tremendo (Eugenio Cambaceres, 1884).

Todo lo dicho nos permite observar una conformación a retazos del cuerpo femenino que, a diferencia de la estética decadentista a la que se suele ligar la escritura de este autor, no se une dicho cuerpo con la mujer fatal, etérea y punzante, ni con la mujer monstruosa (por mucho que bromee el narrador de Pot-pourri con sus metáforas animalescas para hablar sobre ellas). Tampoco, como se ha destacado en el segundo apartado de este trabajo, se podría ligar de manera irreductible al cuerpo femenino con la representación aristocrática de la patria, es decir, con valores intangibles, estáticos y propios de un pasado mítico como lo planteaban Cané y demás representantes de la oligarquía intelectual de la generación del ' 80 .

La imprevisibilidad del cuerpo femenino y su renuencia a permanecer dentro del círculo estereotipado de la mirada masculina actuarán en la narrativa de Cambaceres como metáfora de los cambios acaecidos en la so-

${ }^{12}$ Cané, Miguel, "De cepa criolla”, 1884, en Prosa ligera (1919). Reproducido fragmentariamente en Terán (2008). 
ciedad y como crisis de la representación anacrónica y melancólica que se tenía sobre la patria. Esta, que liga inextricablemente el sentimiento de pertenencia al país con el accionar ideal y divino de las mujeres, debe, según la narrativa de este escritor, actualizarse y reconfigurarse.

Entre el ser y el parecer, con sus máscaras, disfraces y carnavales, este autor construye un cuerpo femenino hecho de pedazos, como un "collage" que es pura combinación de ideas preconcebidas, acciones y sorpresas. Nunca estático, en constante movimiento, este cuerpo es un modelo para armar por un narrador que no maniobra las piezas sino que sólo las observa y deja que se choquen, entrelacen, mezclen y fusionen paródica, trágica, y sobre todo, ficcionalmente. En esta perspectiva la mujer no podría asimilarse a la gran aldea o familia añorada y rememorada por escritores como López y Cané ya que las figuras femeninas de las obras de Cambaceres no se ligan con un formato modélico y alejado de la dinámica moderna, sino que se metamorfosean, se disfrazan y se burlan de las instancias de poder (como son el matrimonio, la familia y la república). Dentro de esta perspectiva, los cambios sociales y políticos acaecidos habilitan un nuevo estilo narrativo así como también impulsan el desenmascaramiento de la farsa familiar y republicana a través del muestreo del accionar femenino que se escabulle del círculo protegido del hogar y reclama su lugar en el comercio de los sentimientos.

\section{REFERENCIAS}

Botana, Natalio. (1985). El orden conservador. Buenos Aires: Editorial Sudamericana.

Calzadilla, Santiago. (1982). Las beldades de mi tiempo. Buenos Aires: Centro Editor de América Latina.

Cambaceres, Eugenio. (1884). Música sentimental. Silbidos de un vago. París: Librería Española y Americana E. Denné [en línea]. Disponible en http://www.scribd.com/users/Barricadas/documents_collections. Consulta: 23.05.2013.

- (1980). Sin rumbo. Buenos Aires: Centro Editor de América Latina. . (2001). Pot-pourri. Silbidos de un vago. Prólogo de Claudia Torre.

Barcelona: Edit. Sol 90, La Biblioteca Argentina. . (2007). En la sangre. Buenos Aires: Editorial Colihue.

Cymerman, Claudio. (1973-1974). Eugenio Cambaceres: novelista y crítico. Anales de Literatura Hispanoamericana, 2-3, 363-386.

D’Amico, Carlos. (1977). Buenos Aires, sus hombres, su política (1860-1890). 
Buenos Aires: Centro Editor de América Latina.

García, Susana y Panesi, Jorge. (2007). Introducción a En la sangre (pp. 1747). Buenos Aires: Edit. Colihue.

Groussac, Paul. (1972). Los que pasaban. Buenos Aires: Librería Huemul. Iglesia, Cristina. (2003). Breve tratado sobre el silbido en la literatura nacional. En La violencia del azar, ensayo sobre literatura argentina (pp. 347354). Buenos Aires: Fondo de Cultura Económica.

Jitrik, Noé. (1997). Cambaceres: adentro y afuera. En Suspender toda certeza (pp.17-31). Buenos Aires: Edit. Biblos.

Marun, Gioconda. (1986). Relectura de Sin Rumbo: floración de la novela moderna. Revista Iberoamericana, LII, 135-136, 379-392.

Laera, Alejandra. (2004). El tiempo vacío de la ficción. Buenos Aires: Fondo de Cultura Económica.

Panesi, Jorge. (2004). Cambaceres, un narrador chismoso. En Críticas (pp. 275-285). Buenos Aires: Edit. Norma.

Ramos, Julio. (2003). Desencuentros de la modernidad en América Latina. Buenos Aires: Fondo de Cultura Económica.

Solodkow, David. (2011). La oligarquía violada: Etnografía naturalista, xenofobia y alarma social en la última novela de Eugenio Cambaceres. En la sangre (1887). Decimonónica, 8, 1, 93-112.

Terán, Oscar. (2000). El lamento de Cané. En Vida intelectual en el Buenos Aires de fin de siglo (1880-1910) (pp. 109-126). Buenos Aires: Fondo de Cultura Económica.

. (2008). Lección 4. El 80. Miguel Cané (h). En Historia de las ideas en la Argentina: diez lecciones iniciales, 1810-1980 (pp. 109-126). Buenos Aires: Siglo XXI Editores, Biblioteca básica de historia.

Torre, Claudia. (2001). Prólogo. En Cambaceres, Eugenio, Pot-pourri. Silbidos de un vago. Barcelona: Edit. Sol 90, La Biblioteca Argentina. 